\title{
CONTROLE QUÍMICO DE MILHO RESISTENTE AO GLYPHOSATE PROVENIENTE DE DIFERENTES HÍBRIDOS
}

\author{
LUCAS BRAGA PEREIRA BRAZ ${ }^{1}$, GUILHERME BRAGA PEREIRA BRAZ1 ${ }^{1}$, \\ SERGIO DE OLIVEIRA PROCÓPIO², ALESSANDRO GUERRA DA SILVA ${ }^{1}$, \\ ANTONIO JOAQUIM BRAGA PEREIRA BRAZ ${ }^{1}$ e CAMILA JORGE BERNABÉ FERREIRA ${ }^{1}$
}

${ }^{1}$ Universidade de Rio Verde, Rio Verde-GO,Brasil.E-mail: lucasbpbraz@gmail.com,
guilhermebrag@gmail.com,silvaag@yahoo.com.br,braz@unirv.edu.br; camilajbferreira@gmail.com
${ }^{2}$ EmbrapaTabuleiros Costeiros, Aracaju-SE,Brasil.E-mail:procopio.so@gmail.com

Revista Brasileira de Milho e Sorgo, v.17, n.3, p. 535-547, 2018

\begin{abstract}
RESUMO - As plantas voluntárias de milho podem causar perdas quando em convivência com outras culturas, tornando-se necessário proceder seu controle. Neste sentido, diferentes estratégias podem ser utilizadas, destacandose o manejo químico. O objetivo desse trabalho foi avaliar a suscetibilidade de híbridos de milho $\mathrm{RR}^{\circledR}$ ao controle químico com aplicação de herbicidas em pós-emergência. O experimento foi conduzido em campo, utilizando-se o delineamento de blocos casualizados, em esquema de parcelas subdivididas, com quatro repetições. Na parcela principal foram avaliados oito tratamentos compostos pela aplicação de clethodim + glyphosate, quizalofop-p-ethyl + glyphosate, clodinafop + glyphosate, imazethapyr + glyphosate, [imazamox + bentazon] + glyphosate, cloransulan + glyphosate, glyphosate e testemunha sem aplicação. Nas subparcelas foram semeados nove híbridos de milho RR ${ }^{\mathbb{}}$. Tratamentos contendo [imazamox + bentazon] ou cloransulan não foram eficientes no controle de plantas de milho $\mathrm{RR}^{\circledR}$ em estádio V6. O imazethapyr associado ao glyphosate foi eficiente no controle de plantas de milho dos híbridos DKB390, SYN7025 e CD384, os quais mostram maior suscetibilidade a esse herbicida em comparação aos demais híbridos. Plantas provenientes de todos os híbridos avaliados, no estádio V6, podem ser totalmente controladas com a aplicação dos herbicidas quizalofop-p-ethyl, clodinafop e clethodim, contudo, clethodim apresentou ação mais lenta. Palavras-chave: herbicidas, plantas voluntárias, pós-emergência, Zea mays.
\end{abstract}

\section{CHEMICAL CONTROL IN DIFFERENT GLYPHOSATE RESISTANT MAIZE HYBRIDS}

\begin{abstract}
Volunteer corn plants can cause high losses when in coexistence with other crops, making necessary its control. In this sense, different strategies can be used, emphasizing the chemical management. The objective of this work was to evaluate the susceptibility of $\mathrm{RR}^{\circledR}$ corn hybrids to chemical control with post-emergence herbicides. The experiment was carried out at field, using a randomized complete block design in a split plots scheme, with four replications. In the main plot, eight treatments were evaluated using clethodim + glyphosate, quizalofop-p-ethyl + glyphosate, clodinafop + glyphosate, imazethapyr + glyphosate, [imazamox + bentazon] + glyphosate, cloransulan + glyphosate, glyphosate, and a control without herbicide application. In the subplots, nine $\mathrm{RR}^{\circledR}$ corn hybrids were sown. Treatments with [imazamox + bentazon] and cloransulan were not efficient in the control of $\mathrm{RR}^{\circledR}$ corn plants at V6 stage. The imazethapyr treatment associated to glyphosate was efficient in controlling the corn hybrids DKB390, SYN7025, and CD384, which showed greater susceptibility to this herbicide compared to the other hybrids evaluated. Plants of all evaluated hybrids can be controlled at V6 with the application of quizalofop-p-ethyl, clodinafop, and clethodim, however, clethodim presented slower action.
\end{abstract}

Keywords: herbicides, volunteer plants, post-emergence, Zea mays. 
A utilização exclusiva do sistema de sucessão de culturas entre soja e milho pode trazer problemas como compactação do solo, perda de matéria orgânica, seleção de microrganismos do solo responsáveis pela degradação de pesticidas (menor atividade residual), e plantas voluntárias de uma cultura interferindo no desenvolvimento da outra (Bertol et al., 2004; Gasparim et al., 2005; Zablotowicz et al., 2006; Braz et al., 2013).

Apesar de o milho ser uma espécie de interesse econômico, a partir do momento em que há convivência de plantas voluntárias dessa espécie com a cultura semeada em sucessão, ela passa a se comportar como planta daninha. Nos últimos anos, tem sido comum a ocorrência de plantas voluntárias de milho na soja (Petter et al., 2015; López-Ovejero et al., 2016). Essas plantas podem emergir de sementes com anomalias que foram semeadas em safras anteriores, ou de grãos oriundos de perdas na colheita. $\mathrm{O}$ milho tem potencial para se tornar espécie de difícil controle, especialmente no caso do milho Roundup Ready $\left(\mathrm{RR}^{\circledR}\right)$ voluntário em cultivos de soja que também apresentam resistência ao glyphosate (Costa et al., 2014).

Por este motivo, é fundamental proceder ao controle das plantas voluntárias de milho na cultura da soja, sendo o método químico o mais utilizado, em função de características como facilidade e rápida execução, além de apresentar elevada eficácia (Correia et al., 2011). Dúvidas com relação ao estádio de aplicação mais apropriado, bem como mecanismos de ação de herbicidas que irão apresentar eficácia no controle de plantas voluntárias de milho, ainda existem, apesar de pesquisas já terem sido desenvolvidas com esse propósito (Costa et al., 2014; Petter et al., 2015; López-Ovejero et al., 2016).

Os herbicidas inibidores da ACCase consistem nas alternativas iniciais que devem ser estudadas no intuito de se controlar plantas voluntárias de milho $\mathrm{RR}^{\circledR}$, por causa do espectro de ação que apresentam. Além destes, é fundamental avaliar a eficácia dos herbicidas inibidores da ALS, visto que são amplamente utilizados na soja. Trabalhos realizados com os herbicidas clethodim e fluazifop-p-butyl, aplicados em doses de 84 e 187,5 $\mathrm{g} \mathrm{ha}^{-1}$, respectivamente, demonstraram a eficácia desses no controle de milho voluntário (Bianchi, 2009).

Além das dúvidas relacionadas aos herbicidas que podem ser utilizados para o controle das plantas voluntárias de milho $\mathrm{RR}^{\circledR}$, há possibilidade de haver tolerância diferencial em relação à suscetibilidade aos herbicidas de híbridos provenientes de diferentes programas de melhoramento. Cavalieri et al. (2008) comprovaram que existe comportamento distinto quanto a sensibilidade para o herbicida nicosulfuron entre os materiais genéticos de milho.

Neste contexto, o objetivo desse trabalho foi avaliar a suscetibilidade de híbridos de milho resistentes ao glyphosate, provenientes de diferentes programas de melhoramento, a aplicações de herbicidas em pós-emergência, e selecionar herbicidas eficientes para seu controle.

O experimento foi conduzido na Fazenda Experimental da Cooperativa Agroindustrial dos Produtores Rurais do Sudoeste Goiano (Comigo), localizada no município de Rio Verde-GO, latitude $17^{\circ} 45^{\prime} 52,04$ 'S , longitude $51^{\circ} 02^{\prime} 19,68^{\prime \prime} \mathrm{O}$ e altitude de $830 \mathrm{~m}$. O experimento foi conduzido de 06/03/2015 a 30/05/2015.

$\mathrm{O}$ solo da área experimental foi classificado como Latossolo Vermelho distroférrico (Santos et al., 2013), de textura argilo-arenosa, apresentando as seguintes características na camada de $0-20 \mathrm{~cm}: \mathrm{pH}$ em $\mathrm{CaCl}_{2}=5,5 ;$ M.O. $=26 \mathrm{~g} \mathrm{~kg}^{-1} ; 531 \mathrm{~g} \mathrm{~kg}^{-1}$ de areia; $54 \mathrm{~g} \mathrm{~kg}^{-1}$ de silte e $415 \mathrm{~g} \mathrm{~kg}^{-1}$ de argila. Segundo a 
classificação de Köppen, o clima para a localidade é do tipo Aw, tropical com estação seca, sendo caracterizado por apresentar chuvas mais intensas no verão em comparação com o inverno. As precipitações e temperaturas médias observadas durante a condução do experimento encontram-se na Figura 1.

Anteriormente à instalação do experimento, a área havia sido cultivada com soja em condições de safra (2014/2015). Após a colheita da soja, a área foi dessecada quimicamente em 15/01/2015, utilizando a associação entre os herbicidas glyphosate $(720 \mathrm{~g}$ e.a. ha-1 $\left.{ }^{-1}\right)+$ fenoxaprop-p-ethyl $\left(55 \mathrm{~g}\right.$. ha $\left.{ }^{-1}\right)$. Antes da semeadura do milho, no dia 02/03/2015, uma nova aplicação foi realizada visando eliminar novo fluxo de plantas daninhas emergidas na área experimental, utilizando nesta operação apenas o herbicida glyphosate na dose de 720 g e.a. ha ${ }^{-1}$.

O delineamento experimental utilizado foi o de blocos casualizados, em esquema de parcelas subdi- vididas, com quatro repetições. Na parcela principal foram avaliados 8 tratamentos herbicidas, constando entre estes uma testemunha sem aplicação, servindo ela como referência nas avaliações de controle (Tabela 1). Nas subparcelas foram semeados 9 híbridos de milho $\mathrm{RR}^{\circledR}$ oriundos de diferentes tipos de cruzamentos e programas de melhoramento, sendo estes: AS 1633 PRO2, 30S31 YHR, 30F53 YHR, SYN 7205 TL/TG, DKB 177 PRO 3, DKB 390 PRO 3 e 2B587 PW (híbridos simples); CD 384 PW (híbrido triplo); e CD 3612 PW (híbrido simples modificado). As unidades experimentais apresentavam 4 linhas semeadas com milho, com $4 \mathrm{~m}$ de comprimento, espaçadas $0,5 \mathrm{~m}$ entre si, sendo considerada área útil para avaliação as 2 linhas centrais, descontando $0,5 \mathrm{~m}$ das extremidades $\left(3 \mathrm{~m}^{2}\right)$.

A semeadura de milho (06/03/2015) foi realizada manualmente depositando-se 5 sementes por metro, a fim de se obter uma população final de 100 mil plantas ha-1. Não foi realizada adubação no sulco

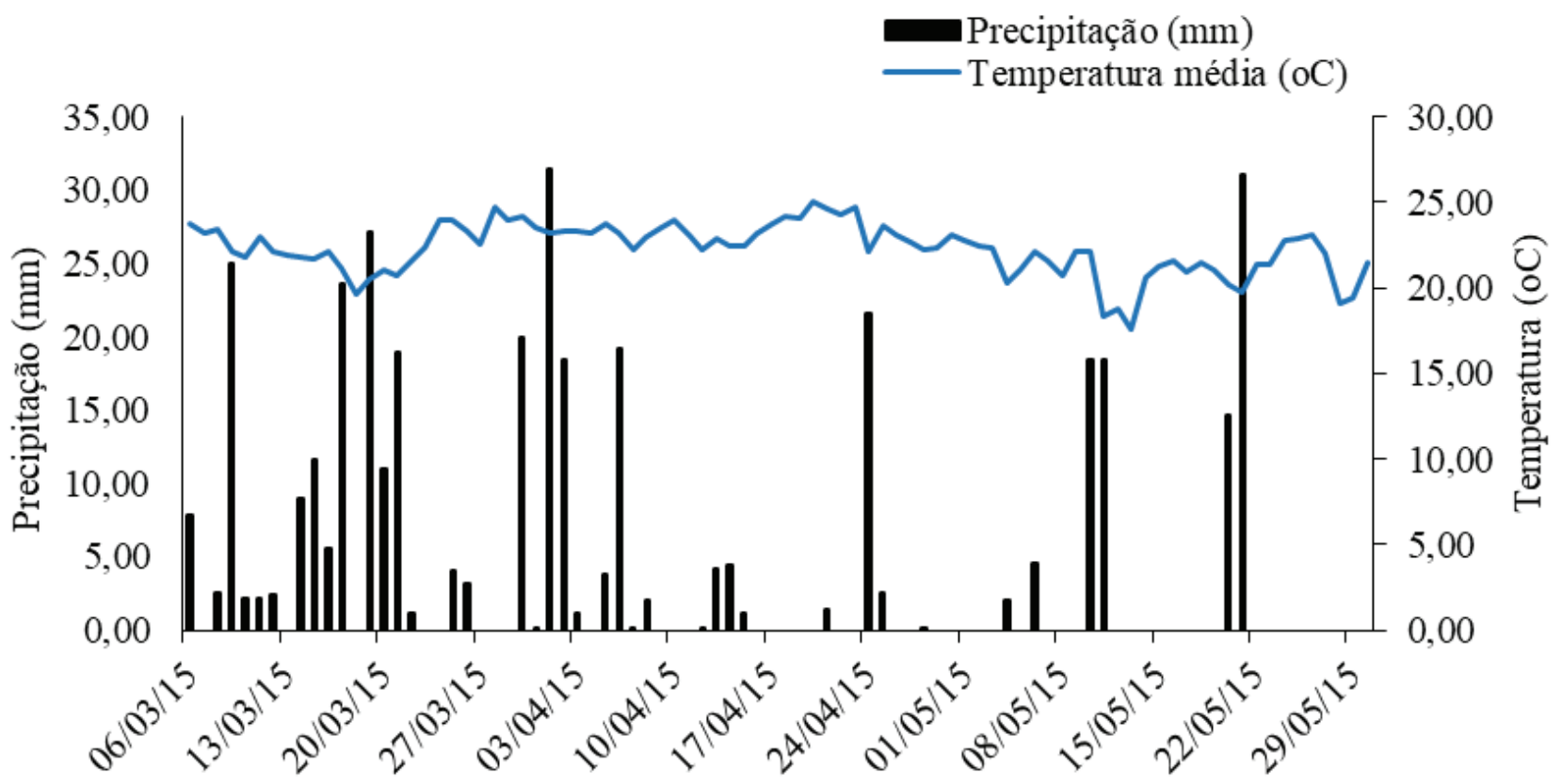

Figura 1. Dados de precipitação pluvial $(\mathrm{mm})$ e temperatura média $\left({ }^{\circ} \mathrm{C}\right)$ durante o período de condução do experimento. Rio Verde-GO, 2015. 
Tabela 1. Relação dos tratamentos herbicidas aplicados em pós-emergência visando o controle de plantas voluntárias de milho $\mathrm{RR}^{\circledR}$. Rio Verde-GO, 2015.

\section{Tratamentos}

Testemunha sem herbicida

Clethodim + glyphosate ${ }^{2}$

Quizalofop-p-ethyl + glyphosate ${ }^{1}$

Clodinafop-propargyl + glyphosate ${ }^{3}$

Imazethapyr + glyphosate ${ }^{4}$

[Imazamox + bentazon] + glyphosate $^{2}$

Cloransulan + glyphosate $^{5}$

Glyphosate $^{1}$
Dose

(g i.a. ou e.a. $\left.\mathrm{ha}^{-1}\right)$

$96+720$

$75+720$

$48+720$

$106+720$

$[28+60]+720$

$33,6+720$

720

${ }^{1}$ Não foram adicionados adjuvantes à calda de aplicação; ${ }^{2}$ Adicionado Assist a $0,5 \% \mathrm{v} \mathrm{v}^{-1}$ à calda de aplicação; ${ }^{3}$ Adicionado Nimbus a $0,5 \% \mathrm{~V} \mathrm{v}^{-1}$ à calda de aplicação; ${ }^{4}$ Adicionado Assist a $1 \% \mathrm{~V} \mathrm{~V}^{-1}$ à calda de aplicação; ${ }^{5}$ Adicionado Agral a $0,2 \% \mathrm{~V} \mathrm{~V}$ à calda de aplicação.

de semeadura do milho por se tratar de experimento visando o controle de plantas voluntárias desta espécie, simulando as condições nas quais estas plantas se encontram na ocasião em que se procede o controle. A emergência das plântulas de milho ocorreu 5 dias após a semeadura.

A partir do vigésimo dia após a semeadura do milho, período no qual houve um fluxo de emergência da comunidade infestante, todas as parcelas foram mantidas capinadas até o término do experimento, para que não houvesse nenhum tipo de interferência das plantas daninhas nos tratamentos, sendo avaliado apenas o efeito dos herbicidas sobre o desenvolvimento das plantas de milho.

A aplicação dos tratamentos herbicidas foi realizada em pós-emergência das plantas no dia 12/04/2015 (32 dias após a emergência do milho). Nesta ocasião, as plantas dos diferentes híbridos avaliados encontravam-se em estádio fenológico V6 (altura média de $75 \mathrm{~cm}$ ). Para esta operação utilizou-se um pulverizador costal de pressão constante à base de $\mathrm{CO}_{2}$ (35 $\left.\mathrm{lb} \mathrm{pol}^{-2}\right)$ equipado com quatro pontas de pulverização do tipo XR 110.02, espaçadas em 0,5 m, proporcionando um volume de aplicação equivalente a $150 \mathrm{~L} \mathrm{ha}^{-1}$ de calda. As aplicações foram realizadas sob umidade relativa do ar, temperatura e velocidade do vento média de $63,7 \%, 23,4{ }^{\circ} \mathrm{C}$ e $3,4 \mathrm{~km} \mathrm{~h}^{-1}$, respectivamente.

Para avaliar a eficácia dos diferentes tratamentos no manejo químico das plantas de milho foram realizadas avaliações de porcentagem de controle aos $7,14,21,28,35$ e 48 dias após a aplicação dos herbicidas (DAA), de acordo com escala proposta pela Velini et al. (1995). Além destas avaliações, aos 7, 28 e 48 DAA foram realizadas avaliações de altura das plantas de milho, medindo a distância entre o colo da planta até o ápice da última folha expandida, sendo amostradas cinco plantas por unidade experimental.

As análises estatísticas foram realizadas com o programa computacional Sisvar (Ferreira, 2011). Os dados foram submetidos à análise de variância. Quando foi observado efeito significativo entre os fatores testados ou entre os níveis de cada fator, aplicou-se o teste de agrupamento de médias de Scott-Knott a 5\%.

A Tabela 2 apresenta os resultados referentes à porcentagem de controle aos 7 e 14 DAA dos diferentes tratamentos herbicidas visando ao manejo químico de plantas de milho $\mathrm{RR}^{\circledR}$. 
Tabela 2. Controle químico de plantas de milho $\mathrm{RR}^{\circledR}$, avaliado visualmente aos 7 e 14 dias após a aplicação de diferentes tratamentos herbicidas. Rio Verde-GO, 2015.

\begin{tabular}{|c|c|c|c|c|c|c|c|c|c|c|c|c|c|c|c|c|}
\hline \multirow{3}{*}{$\begin{array}{c}\text { Híbrido } \\
\text { AS1633 }\end{array}$} & \multicolumn{16}{|c|}{ Controle $(\%)-7$ DAA } \\
\hline & \multicolumn{2}{|c|}{ Testemunha } & \multicolumn{2}{|c|}{ CLE+GLY } & \multicolumn{2}{|c|}{ QUI+GLY } & \multicolumn{2}{|c|}{ CLO+GLY } & \multicolumn{2}{|c|}{ IMZ+GLY } & \multicolumn{2}{|c|}{$[\mathrm{IMX}+\mathrm{BEN}]+\mathrm{GLY}$} & \multicolumn{2}{|c|}{ CLS+GLY } & \multicolumn{2}{|c|}{ GLY } \\
\hline & 0 & $\mathrm{Da}$ & 23 & $\mathrm{Bc}$ & 35 & $\mathrm{Aa}$ & 31 & Ac & 24 & $\mathrm{Ba}$ & 20 & $\mathrm{Ba}$ & 13 & $\mathrm{Ca}$ & 12 & $\overline{\mathrm{Ca}}$ \\
\hline CD384 & 0 & $\mathrm{Ea}$ & 28 & Ac & 28 & $\mathrm{Ab}$ & 30 & Ac & 18 & $\mathrm{Bb}$ & 17 & $\mathrm{Bb}$ & 12 & $\mathrm{Ca}$ & 6 & Da \\
\hline CD3612 & 0 & $\mathrm{Ea}$ & 27 & Ac & 30 & $\mathrm{Ab}$ & 30 & Ac & 20 & $\mathrm{Ba}$ & 15 & $\mathrm{Cb}$ & 11 & $\mathrm{Ca}$ & 6 & $\mathrm{Da}$ \\
\hline $30 \mathrm{~S} 31$ & 0 & $\mathrm{Da}$ & 31 & $\mathrm{Ab}$ & 34 & Aa & 29 & Ac & 16 & $\mathrm{Bb}$ & 17 & $\mathrm{Bb}$ & 12 & $\mathrm{Ba}$ & 8 & $\mathrm{Ca}$ \\
\hline 30F53 & 0 & $\mathrm{Fa}$ & 36 & $\mathrm{Ba}$ & 39 & $\mathrm{Ba}$ & 50 & $\mathrm{Aa}$ & 23 & $\mathrm{Ca}$ & 18 & $\mathrm{Db}$ & 16 & $\mathrm{Da}$ & 10 & $\mathrm{Ea}$ \\
\hline SYN7205 & 0 & $\mathrm{Ea}$ & 37 & $\mathrm{Aa}$ & 38 & $\mathrm{Aa}$ & 34 & $\mathrm{Ab}$ & 21 & $\mathrm{Ba}$ & 21 & $\mathrm{Ba}$ & 15 & $\mathrm{Ca}$ & 10 & Da \\
\hline DKB177 & 0 & $\mathrm{Ea}$ & 27 & Ac & 27 & $\mathrm{Ab}$ & 30 & Ac & 21 & $\mathrm{Ba}$ & 20 & $\mathrm{Ba}$ & 15 & $\mathrm{Ca}$ & 8 & $\mathrm{Da}$ \\
\hline DKB390 & 0 & $\mathrm{Ea}$ & 24 & $\mathrm{Bc}$ & 22 & $\mathrm{Bc}$ & 27 & Ac & 21 & $\mathrm{Ba}$ & 20 & $\mathrm{Ba}$ & 11 & $\mathrm{Ca}$ & 7 & $\mathrm{Da}$ \\
\hline 2B587 & 0 & $\mathrm{Ea}$ & 34 & $\mathrm{Ab}$ & 36 & $\mathrm{Aa}$ & 33 & $\mathrm{Ab}$ & 23 & $\mathrm{Ba}$ & 22 & $\mathrm{Ba}$ & 15 & $\mathrm{Ca}$ & 8 & \\
\hline CV (\%) & \multicolumn{16}{|c|}{35,04} \\
\hline \multirow{2}{*}{ Híbrido } & \multicolumn{16}{|c|}{ Controle $(\%)-14$ DAA } \\
\hline & \multicolumn{2}{|c|}{ Testemunha } & \multicolumn{2}{|c|}{ CLE+GLY } & \multicolumn{2}{|c|}{ QUI+GLY } & \multicolumn{2}{|c|}{ CLO+GLY } & \multicolumn{2}{|c|}{ IMZ+GLY } & \multicolumn{2}{|c|}{$[\mathrm{IMX}+\mathrm{BEN}]+\mathrm{GLY}$} & \multicolumn{2}{|c|}{ CLS+GLY } & \multicolumn{2}{|c|}{ GLY } \\
\hline AS1633 & 0 & $\mathrm{Ea}$ & 19 & $\mathrm{Cc}$ & 87 & $\mathrm{Aa}$ & 38 & $\mathrm{Bd}$ & 32 & $\mathrm{Ba}$ & 29 & $\mathrm{Ba}$ & 13 & $\mathrm{Da}$ & 1 & $\overline{\mathrm{Ea}}$ \\
\hline CD384 & 0 & $\mathrm{Da}$ & 29 & $\mathrm{Bc}$ & 100 & $\mathrm{Aa}$ & 96 & $\mathrm{Aa}$ & 29 & $\mathrm{Ba}$ & 25 & $\mathrm{Ba}$ & 13 & $\mathrm{Ca}$ & 1 & Da \\
\hline CD3612 & 0 & $\mathrm{Ca}$ & 35 & $\mathrm{Bb}$ & 72 & $\mathrm{Ab}$ & 76 & $\mathrm{Ab}$ & 27 & $\mathrm{Ba}$ & 26 & $\mathrm{Ba}$ & 11 & $\mathrm{Ca}$ & 1 & $\mathrm{Ca}$ \\
\hline $30 \mathrm{~S} 31$ & 0 & $\mathrm{Ea}$ & 43 & $\mathrm{Ba}$ & 100 & $\mathrm{Aa}$ & 93 & $\mathrm{Aa}$ & 23 & $\mathrm{Ca}$ & 20 & $\mathrm{Ca}$ & 13 & $\mathrm{Da}$ & 1 & $\mathrm{Ea}$ \\
\hline 30F53 & 0 & $\mathrm{Ea}$ & 46 & $\mathrm{Ba}$ & 96 & $\mathrm{Aa}$ & 98 & $\mathrm{Aa}$ & 28 & $\mathrm{Ca}$ & 25 & $\mathrm{Ca}$ & 14 & $\mathrm{Da}$ & 0 & $\mathrm{Ea}$ \\
\hline SYN7205 & 0 & $\mathrm{Da}$ & 35 & $\mathrm{Bb}$ & 97 & $\mathrm{Aa}$ & 95 & $\mathrm{Aa}$ & 26 & $\mathrm{Ba}$ & 27 & $\mathrm{Ba}$ & 13 & $\mathrm{Ca}$ & 0 & $\mathrm{Da}$ \\
\hline DKB177 & 0 & $\mathrm{Da}$ & 50 & $\mathrm{Ba}$ & 95 & $\mathrm{Aa}$ & 91 & $\mathrm{Aa}$ & 32 & $\mathrm{Ca}$ & 34 & $\mathrm{Ca}$ & 8 & $\mathrm{Da}$ & 1 & Da \\
\hline DKB390 & 0 & $\mathrm{Da}$ & 26 & $\mathrm{Cc}$ & 93 & $\mathrm{Aa}$ & 50 & $\mathrm{Bc}$ & 28 & $\mathrm{Ca}$ & 27 & $\mathrm{Ca}$ & 9 & $\mathrm{Da}$ & 0 & $\mathrm{Da}$ \\
\hline 2B587 & 0 & $\mathrm{Ea}$ & 38 & $\mathrm{Cb}$ & 98 & $\mathrm{Aa}$ & 86 & $\mathrm{Bb}$ & 31 & $\mathrm{Ca}$ & 30 & $\mathrm{Ca}$ & 13 & $\mathrm{Da}$ & 0 & $\mathrm{Ea}$ \\
\hline CV (\%) & & & & & & & & & 6,31 & & & & & & & \\
\hline
\end{tabular}

$\mathrm{CLE}=$ clethodim; QUI = quizalofop-p-ethyl; CLO = clodinafop; IMZ = imazethapyr; $[\mathrm{IMX}+\mathrm{BEN}]=[\mathrm{imazamox}+$ bentazon $]$; $\mathrm{CLS}=$ cloransulan; GLY = glyphosate. * Médias seguidas por letras distintas maiúsculas na linha e minúsculas na coluna diferem entre si pelo teste de Scott-Knott $(\mathrm{p}<0,05)$.

Na primeira avaliação realizada (7 DAA), os herbicidas inibidores da ACCase clethodim, quizalofop-p-ethyl, clodinafop, e os inibidores da ALS imazethapyr, [imazamox + bentazon], cloransulan, todos aplicados em associação com glyphosate, proporcionaram baixos níveis de controle sobre as plantas de milho $\mathrm{RR}^{\circledR}$. No entanto, os herbicidas inibidores da ACCase, de forma geral, promoveram injúrias mais severas aos híbridos de milho, tendo como destaque o tratamento contendo o herbicida clodinafop, que ocasionou nessa avaliação inicial $50 \%$ de controle nas plantas do híbrido 30F53. Esses resultados corroboram com os apresentados por Marca et al. (2015), no qual pode se verificar melhor desempenho inicial dos herbicidas inibidores da ACCase em comparação com os inibidores da ALS visando o controle de plantas voluntárias de milho resistente ao glyphosate.

O glyphosate isolado proporcionou baixos níveis de injúrias às plantas de milho, independentemente do híbrido avaliado. A observação desse comportamento era esperada, visto que todos os híbridos avaliados no presente trabalho apresentaram durante seu processo de desenvolvimento inserção de gene que confere resistência ao herbicida glyphosate.

Aos 14 DAA, a eficiência de controle dos herbicidas aumentou em relação à avaliação realizada aos 7 DAA (Tabela 2). O tratamento contendo quizalofop-p-ethyl com glyphosate proporcionou, de forma geral, os melhores resultados de controle de milho, variando de $72 \%$ para o híbrido CD3612 a $100 \%$ de controle, para o $30 \mathrm{~S} 31$ e para o CD 384. 
A associação de clodinafop com glyphosate também apresentou elevados níveis de controle, com exceção do controle proporcionado para os híbridos AS 1633 e DKB390, que foi igual ou inferior a 50\%.

O tratamento com clethodim associado com glyphosate apresentou resultados de controle variando entre 19 a 50\%, sendo o menos eficiente entre os inibidores da ACCase nesta avaliação. Apesar disto, quando comparado com os tratamentos em que foram utilizados herbicidas inibidores da ALS em associação com glyphosate, verifica-se que o clethodim, de modo geral, teve controle um pouco superior, principalmente quando comparado aos tratamentos contendo cloransulan + glyphosate. O melhor desempenho dos inibidores da ACCase em relação aos inibidores da ALS visando o controle de plantas voluntárias de milho resistente ao glyphosate já foi demonstrado em trabalhos anteriores (Petter et al., 2015; Marca et al., 2015).

Aos 21 DAA, todos os herbicidas inibidores de ACCase em associação com glyphosate apresentaram eficácia no controle das plantas de milho (>80\%), sendo os níveis mais baixos de controle observados com a aplicação da associação entre clethodim + glyphosate (Tabela 3). Marquardt e Johnson (2013) também observaram controle eficiente e similar das plantas de milho $\mathrm{RR}^{\circledR}$ pelo herbicida clethodim (79 $\mathrm{g}$ $\mathrm{ha}^{-1}$ ) aplicado quando elas se encontravam com $30 \mathrm{ou}$ $90 \mathrm{~cm}$ de altura. Nessa avaliação todas as plantas de milho que receberam a aplicação do tratamento contendo quizalofop-p-ethyl com glyphosate, independentemente do híbrido, estavam mortas.

Tabela 3. Controle químico de plantas de milho $\mathrm{RR}^{\circledR}$, avaliado visualmente aos 21 e 28 dias após a aplicação de diferentes tratamentos herbicidas. Rio Verde-GO, 2015.

\begin{tabular}{|c|c|c|c|c|c|c|c|c|c|c|c|c|c|c|c|c|}
\hline \multirow{3}{*}{$\begin{array}{l}\text { Híbrido } \\
\text { AS1633 }\end{array}$} & \multicolumn{16}{|c|}{ Controle $(\%)-21$ DAA } \\
\hline & \multicolumn{2}{|c|}{ Testemunha } & \multicolumn{2}{|c|}{ CLE+GLY } & \multicolumn{2}{|c|}{ QUI+GLY } & \multicolumn{2}{|c|}{$\mathrm{CLO}+\mathrm{GLY}$} & \multicolumn{2}{|c|}{ IMZ+GLY } & \multicolumn{2}{|c|}{$[\mathrm{IMX}+\mathrm{BEN}]+\mathrm{GLY}$} & \multicolumn{2}{|c|}{ CLS+GLY } & \multicolumn{2}{|c|}{ GLY } \\
\hline & 0 & $\mathrm{Fa}$ & 81 & $\mathrm{Cc}$ & 100 & $\mathrm{Aa}$ & 93 & $\mathrm{Bb}$ & 36 & $\mathrm{Db}$ & 38 & $\mathrm{Db}$ & 14 & $\mathrm{Ea}$ & 0 & $\mathrm{Fa}$ \\
\hline CD384 & 0 & $\mathrm{Ea}$ & 81 & $\mathrm{Bc}$ & 100 & $\mathrm{Aa}$ & 100 & $\mathrm{Aa}$ & 37 & $\mathrm{Cb}$ & 39 & $\mathrm{Cb}$ & 10 & $\mathrm{Da}$ & 0 & $\mathrm{Ea}$ \\
\hline CD3612 & 0 & $\mathrm{Fa}$ & 90 & $\mathrm{Bb}$ & 100 & $\mathrm{Aa}$ & 100 & $\mathrm{Aa}$ & 37 & $\mathrm{Cb}$ & 33 & Dc & 9 & $\mathrm{~Eb}$ & 0 & $\mathrm{Fa}$ \\
\hline $30 \mathrm{~S} 31$ & 0 & $\mathrm{Ea}$ & 91 & $\mathrm{Bb}$ & 100 & $\mathrm{Aa}$ & 100 & $\mathrm{Aa}$ & 28 & $\mathrm{Cc}$ & 27 & $\mathrm{Cd}$ & 11 & $\mathrm{Da}$ & 0 & $\mathrm{Ea}$ \\
\hline $30 \mathrm{~F} 53$ & 0 & $\mathrm{Da}$ & 96 & $\mathrm{Aa}$ & 100 & $\mathrm{Aa}$ & 100 & $\mathrm{Aa}$ & 39 & $\mathrm{Bb}$ & 38 & $\mathrm{Bb}$ & 11 & $\mathrm{Ca}$ & 0 & \\
\hline SYN7205 & 0 & $\mathrm{Ea}$ & 81 & $\mathrm{Bc}$ & 100 & $\mathrm{Aa}$ & 100 & $\mathrm{Aa}$ & 35 & $\mathrm{Cb}$ & 35 & $\mathrm{Cc}$ & 13 & $\mathrm{Da}$ & 0 & $\mathrm{Ea}$ \\
\hline DKB177 & 0 & $\mathrm{Ea}$ & 95 & $\mathrm{Ba}$ & 100 & $\mathrm{Aa}$ & 100 & $\mathrm{Aa}$ & 44 & $\mathrm{Ca}$ & 42 & $\mathrm{Ca}$ & 5 & $\mathrm{Db}$ & 0 & $\mathrm{Ea}$ \\
\hline DKB390 & 0 & $\mathrm{Ea}$ & 89 & $\mathrm{Bb}$ & 100 & $\mathrm{Aa}$ & 96 & $\mathrm{Ab}$ & 41 & $\mathrm{Ca}$ & 41 & $\mathrm{Ca}$ & 8 & $\mathrm{Db}$ & 0 & $\mathrm{Ea}$ \\
\hline 2B587 & 0 & $\mathrm{Ea}$ & 88 & $\mathrm{Bb}$ & 100 & $\mathrm{Aa}$ & 100 & $\mathrm{Aa}$ & 41 & $\mathrm{Ca}$ & 43 & $\mathrm{Ca}$ & 11 & $\mathrm{Da}$ & 0 & $\mathrm{Ea}$ \\
\hline CV (\%) & \multicolumn{16}{|c|}{13,50} \\
\hline \multirow{2}{*}{ Híbrido } & \multicolumn{16}{|c|}{ Controle $(\%)-28$ DAA } \\
\hline & \multicolumn{2}{|c|}{ Testemunha } & \multicolumn{2}{|c|}{ CLE+GLY } & \multicolumn{2}{|c|}{ QUI+GLY } & \multicolumn{2}{|c|}{$\mathrm{CLO}+\mathrm{GLY}$} & \multicolumn{2}{|c|}{ IMZ+GLY } & \multicolumn{2}{|c|}{$[\mathrm{IMX}+\mathrm{BEN}]+\mathrm{GLY}$} & \multicolumn{2}{|c|}{ CLS+GLY } & \multicolumn{2}{|c|}{ GLY } \\
\hline AS1633 & 0 & $\mathrm{Ea}$ & 93 & $\mathrm{Bc}$ & 100 & $\mathrm{Aa}$ & 100 & $\mathrm{Aa}$ & 40 & $\mathrm{Cc}$ & 42 & $\mathrm{Cc}$ & 9 & $\mathrm{Db}$ & 0 & $\overline{\mathrm{Ea}}$ \\
\hline CD384 & 0 & $\mathrm{Ea}$ & 96 & $\mathrm{Bb}$ & 100 & $\mathrm{Aa}$ & 100 & $\mathrm{Aa}$ & 49 & $\mathrm{Cb}$ & 50 & $\mathrm{Ca}$ & 13 & $\mathrm{Da}$ & 0 & $\mathrm{Ea}$ \\
\hline CD3612 & 0 & $\mathrm{Ea}$ & 100 & $\mathrm{Aa}$ & 100 & $\mathrm{Aa}$ & 100 & $\mathrm{Aa}$ & 50 & $\mathrm{Bb}$ & 43 & $\mathrm{Cc}$ & 8 & $\mathrm{Db}$ & 0 & $\mathrm{Ea}$ \\
\hline $30 \mathrm{~S} 31$ & 0 & $\mathrm{Ea}$ & 100 & $\mathrm{Aa}$ & 100 & $\mathrm{Aa}$ & 100 & $\mathrm{Aa}$ & 38 & $\mathrm{Bc}$ & 36 & $\mathrm{Cd}$ & 8 & $\mathrm{Db}$ & 0 & $\mathrm{Ea}$ \\
\hline $30 F 53$ & 0 & $\mathrm{Da}$ & 100 & $\mathrm{Aa}$ & 100 & $\mathrm{Aa}$ & 100 & $\mathrm{Aa}$ & 49 & $\mathrm{Bb}$ & 47 & $\mathrm{Bb}$ & 10 & $\mathrm{Cb}$ & 0 & \\
\hline SYN7205 & 0 & $\mathrm{Da}$ & 99 & $\mathrm{Aa}$ & 100 & $\mathrm{Aa}$ & 100 & $\mathrm{Aa}$ & 49 & $\mathrm{Bb}$ & 49 & $\mathrm{Bb}$ & 12 & $\mathrm{Ca}$ & 0 & $\mathrm{Da}$ \\
\hline DKB177 & 0 & $\mathrm{Da}$ & 100 & $\mathrm{Aa}$ & 100 & $\mathrm{Aa}$ & 100 & $\mathrm{Aa}$ & 51 & $\mathrm{Ba}$ & 47 & $\mathrm{Cb}$ & 3 & Dc & 0 & $\mathrm{Da}$ \\
\hline DKB390 & 0 & $\mathrm{Ca}$ & 100 & $\mathrm{Aa}$ & 100 & $\mathrm{Aa}$ & 100 & $\mathrm{Aa}$ & 54 & $\mathrm{Ba}$ & 53 & $\mathrm{Ba}$ & 3 & $\mathrm{Cc}$ & 0 & \\
\hline 2B587 & 0 & $\mathrm{Da}$ & 100 & $\mathrm{Aa}$ & 100 & $\mathrm{Aa}$ & 100 & $\mathrm{Aa}$ & 49 & $\mathrm{Bb}$ & 51 & $\mathrm{Ba}$ & 10 & $\mathrm{Cb}$ & 0 & $\mathrm{Da}$ \\
\hline CV (\%) & & & & & & & & & & & & & & & & \\
\hline
\end{tabular}

$\mathrm{CLE}=$ clethodim; QUI = quizalofop-p-ethyl; CLO = clodinafop; IMZ = imazethapyr; $[\mathrm{IMX}+\mathrm{BEN}]=[$ imazamox + bentazon $]$; CLS = cloransulan; GLY = glyphosate. *Médias seguidas por letras distintas maiúsculas na linha e minúsculas na coluna diferem entre si pelo teste de Scott-Knott $(\mathrm{p}<0,05)$. 
A eficácia observada no presente trabalho dos diferentes inibidores da ACCase avaliados em controlar plantas de milho corrobora os resultados apresentados por Marca et al. (2015). No referido trabalho, os autores concluíram que todos os herbicidas inibidores da ACCase avaliados (haloxyfop-p-methyl - $54 \mathrm{~g} \mathrm{ha}^{-1}$; fenoxaprop-p-ethyl - 96,25 $\mathrm{g} \mathrm{ha}^{-1}$; cyhalofop-butyl - 247,5 $\mathrm{g} \mathrm{ha}^{-1}$; fluazifop-p-butyl - 156,25 $\mathrm{g}$ $\mathrm{ha}^{-1}$; tepraloxydim - 87,5 $\mathrm{g} \mathrm{ha}^{-1}$; e sethoxydim - $207 \mathrm{~g}$ $\mathrm{ha}^{-1}$ ), aplicados isoladamente, apresentam eficácia no controle de milho $\mathrm{RR}^{\circledR}$ em aplicações realizadas sob plantas em estádio V3.

Os tratamentos com imazethapyr e [imazamox + bentazon], em associação com glyphosate, apresentaram nesta avaliação (21 DAA) baixa porcentagem de controle, verificando níveis variando entre 27 e $43 \%$. Dentre os herbicidas inibidores da ALS, o cloransulan consistiu naquele com pior desempenho visando o controle do milho. Destaca-se ainda nesta avaliação que nenhum sintoma foi mais detectado nas plantas de milho, de todos híbridos, nas parcelas onde houve a aplicação isolada do herbicida glyphosate.

Aos 28 DAA, nas parcelas que receberam a combinação dos herbicidas clodinafop com glyphosate, foi observado resultado semelhante ao encontrado nas avaliações anteriores em relação ao tratamento quizalofop-p-ethyl com glyphosate, na qual todas as plantas de todos os híbridos de milho avaliadas foram controladas 100\% (plantas mortas). Com a utilização dos herbicidas clethodim + glyphosate foi verificado aumento no controle em relação às avaliações anteriores, com controle superior a $92 \%$ em todos os híbridos que receberam esse tratamento (Tabela 3). A justificativa para esses resultados é que os herbicidas inibidores de ACCase promoverem a inibição desta enzima, ocasionando um bloqueio da síntese de lipídeos nas plantas suscetíveis (Burke et al., 2006). A partir disso, efeitos negativos começam a afetar a formação da parede celular, especialmente nas regiões em crescimento (Nalewaja et al., 1994).

Pequena evolução no controle dos híbridos de milho foi verificada, aos 28 DAA, nas parcelas pulverizadas com imazethapyr ou [imazamox + bentazon], ambos em associação com glyphosate, mas ainda em nível não satisfatório de controle. Nesta avaliação foi observado um início de recuperação das plantas de milho provenientes de alguns híbridos da baixa intoxicação gerada pela aplicação do herbicida cloransulan + glyphosate (Tabela 3).

Nas duas últimas avaliações (35 e 48 DAA) da porcentagem de controle das plantas de milho $\mathrm{RR}^{\circledR}$ (Tabela 4) é possível constatar que todos os herbicidas inibidores da ACCase associado com o glyphosate, apresentaram excelente controle. Apenas para o híbrido AS1633 não ocorreu o controle total das plantas de milho quando se utilizou o herbicida clethodim com glyphosate, mesmo assim o nível de controle apresentado foi bastante satisfatório (98\%). Costa et al. (2014) relatam que o herbicida clethodim isolado e em mistura com o 2,4-D ou com fluroxypyr não foi eficiente no controle das plantas de milho $\mathrm{RR}^{\circledR}$ em $\mathrm{V} 8$, todavia quando as aplicações foram realizadas em V5, o controle apresentado pelo clethodim isolado ou em mistura foi total.

Os resultados demonstram concordância e até valores superiores com os apresentados por Chahal et al. (2014), que avaliando diferentes herbicidas inibidores da ACCase constataram controle médio de $96 \%$ das plantas de milho $\mathrm{RR}^{\circledR}$ quando essas se encontravam com 2 a 3 folhas e controle médio de $85 \%$ quando a aplicação era realizada com 5 a 6 folhas.

Nas avaliações realizadas aos 35 e 48 DAA continuou sendo observado aumento de controle ocasionado pela ação do herbicida imazethapyr asso- 
Tabela 4. Controle químico de plantas de milho $\mathrm{RR}^{\circledR}$, avaliado visualmente aos 35 e 48 dias após a aplicação de diferentes tratamentos herbicidas. Rio Verde-GO, 2015.

\begin{tabular}{|c|c|c|c|c|c|c|c|c|c|c|c|c|c|c|c|c|}
\hline \multirow{3}{*}{$\frac{\text { Híbrido }}{\text { AS1633 }}$} & \multicolumn{16}{|c|}{ Controle $(\%)-35$ DAA } \\
\hline & \multicolumn{2}{|c|}{ Testemunha } & \multicolumn{2}{|c|}{ CLE+GLY } & \multicolumn{2}{|c|}{ QUI+GLY } & \multicolumn{2}{|c|}{$\mathrm{CLO}+\mathrm{GLY}$} & \multicolumn{2}{|c|}{ IMZ+GLY } & \multicolumn{2}{|c|}{$[\mathrm{IMX}+\mathrm{BEN}]+\mathrm{GLY}$} & \multicolumn{2}{|c|}{ CLS+GLY } & \multicolumn{2}{|c|}{ GLY } \\
\hline & 0 & $\mathrm{Ea}$ & 93 & $\mathrm{Bc}$ & 100 & $\mathrm{Aa}$ & 100 & $\mathrm{Aa}$ & 55 & $\mathrm{Cb}$ & 54 & $\mathrm{Cb}$ & 11 & $\mathrm{Da}$ & 0 & $\overline{\mathrm{Ea}}$ \\
\hline CD384 & 0 & $\mathrm{Fa}$ & 96 & $\mathrm{Bb}$ & 100 & Aa & 100 & $\mathrm{Aa}$ & 60 & $\mathrm{Ca}$ & 55 & $\mathrm{Db}$ & 9 & $\mathrm{Ea}$ & 0 & $\mathrm{Fa}$ \\
\hline CD3612 & 0 & $\mathrm{Ea}$ & 100 & Aa & 100 & Aa & 100 & $\mathrm{Aa}$ & 53 & $\mathrm{Bc}$ & 50 & $\mathrm{Cc}$ & 5 & $\mathrm{Db}$ & 0 & $\mathrm{Ea}$ \\
\hline $30 \mathrm{~S} 31$ & 0 & $\mathrm{Ea}$ & 100 & $\mathrm{Aa}$ & 100 & $\mathrm{Aa}$ & 100 & $\mathrm{Aa}$ & 44 & $\mathrm{Bd}$ & 41 & $\mathrm{Cd}$ & 6 & $\mathrm{Db}$ & 0 & $\mathrm{Ea}$ \\
\hline $30 \mathrm{~F} 53$ & 0 & $\mathrm{Da}$ & 100 & $\mathrm{Aa}$ & 100 & Aa & 100 & Aa & 58 & $\mathrm{Bb}$ & 56 & $\mathrm{Ba}$ & 11 & $\mathrm{Ca}$ & 0 & Da \\
\hline SYN7205 & 0 & $\mathrm{Ea}$ & 100 & $\mathrm{Aa}$ & 100 & $\mathrm{Aa}$ & 100 & $\mathrm{Aa}$ & 61 & $\mathrm{Ba}$ & 58 & $\mathrm{Ca}$ & 9 & $\mathrm{Da}$ & 0 & $\mathrm{Ea}$ \\
\hline DKB177 & 0 & $\mathrm{Ea}$ & 100 & $\mathrm{Aa}$ & 100 & Aa & 100 & $\mathrm{Aa}$ & 55 & $\mathrm{Bb}$ & 49 & $\mathrm{Cc}$ & 3 & Dc & 0 & $\mathrm{Ea}$ \\
\hline DKB390 & 0 & $\mathrm{Da}$ & 100 & Aa & 100 & $\mathrm{Aa}$ & 100 & $\mathrm{Aa}$ & 61 & $\mathrm{Ba}$ & 56 & $\mathrm{Ca}$ & 1 & Dc & 0 & $\mathrm{Da}$ \\
\hline 2B587 & 0 & $\mathrm{Da}$ & 100 & $\mathrm{Aa}$ & 100 & $\mathrm{Aa}$ & 100 & $\mathrm{Aa}$ & 56 & $\mathrm{Bb}$ & 55 & $\mathrm{Bb}$ & 6 & $\mathrm{Cb}$ & 0 & \\
\hline $\mathrm{CV}(\%)$ & \multicolumn{16}{|c|}{4,50} \\
\hline \multirow{2}{*}{ Híbrido } & \multicolumn{16}{|c|}{ Controle $(\%)-48$ DAA } \\
\hline & \multicolumn{2}{|c|}{ Testemunha } & \multicolumn{2}{|c|}{ CLE+GLY } & \multicolumn{2}{|c|}{ QUI+GLY } & \multicolumn{2}{|c|}{$\mathrm{CLO}+\mathrm{GLY}$} & \multicolumn{2}{|c|}{ IMZ+GLY } & \multicolumn{2}{|c|}{$[\mathrm{IMX}+\mathrm{BEN}]+\mathrm{GLY}$} & \multicolumn{2}{|c|}{ CLS+GLY } & \multicolumn{2}{|c|}{ GLY } \\
\hline AS1633 & 0 & $\mathrm{Ea}$ & 98 & $\mathrm{Aa}$ & 100 & $\mathrm{Aa}$ & 100 & $\mathrm{Aa}$ & 60 & $\mathrm{Bd}$ & 55 & $\mathrm{Cd}$ & 9 & $\mathrm{Da}$ & 0 & $\overline{\mathrm{Ea}}$ \\
\hline CD384 & 0 & $\mathrm{Ea}$ & 100 & $\mathrm{Aa}$ & 100 & $\mathrm{Aa}$ & 100 & $\mathrm{Aa}$ & 85 & $\mathrm{Bb}$ & 59 & $\mathrm{Cc}$ & 6 & $\mathrm{Da}$ & 0 & $\mathrm{Ea}$ \\
\hline CD3612 & 0 & $\mathrm{Da}$ & 100 & $\mathrm{Aa}$ & 100 & $\mathrm{Aa}$ & 100 & $\mathrm{Aa}$ & 60 & $\mathrm{Bd}$ & 48 & $\mathrm{Ce}$ & 4 & $\mathrm{Db}$ & 0 & $\mathrm{Da}$ \\
\hline 30S31 & 0 & $\mathrm{Da}$ & 100 & Aa & 100 & $\mathrm{Aa}$ & 100 & $\mathrm{Aa}$ & 46 & $\mathrm{Be}$ & 41 & $\mathrm{Cf}$ & 3 & $\mathrm{Db}$ & 0 & $\mathrm{Da}$ \\
\hline 30F53 & 0 & $\mathrm{Da}$ & 100 & $\mathrm{Aa}$ & 100 & $\mathrm{Aa}$ & 100 & $\mathrm{Aa}$ & 63 & $\mathrm{Bd}$ & 64 & $\mathrm{Bb}$ & 8 & $\mathrm{Ca}$ & 0 & $\mathrm{Da}$ \\
\hline SYN7205 & 0 & $\mathrm{Ea}$ & 100 & $\mathrm{Aa}$ & 100 & $\mathrm{Aa}$ & 100 & $\mathrm{Aa}$ & 92 & $\mathrm{Ba}$ & 74 & $\mathrm{Ca}$ & 8 & $\mathrm{Da}$ & 0 & $\mathrm{Ea}$ \\
\hline DKB177 & 0 & $\mathrm{Da}$ & 100 & $\mathrm{Aa}$ & 100 & $\mathrm{Aa}$ & 100 & $\mathrm{Aa}$ & 69 & $\mathrm{Bc}$ & 49 & $\mathrm{Ce}$ & 0 & $\mathrm{Db}$ & 0 & $\mathrm{Da}$ \\
\hline DKB390 & 0 & $\mathrm{Da}$ & 100 & $\mathrm{Aa}$ & 100 & $\mathrm{Aa}$ & 100 & $\mathrm{Aa}$ & 95 & $\mathrm{Ba}$ & 65 & $\mathrm{Cb}$ & 0 & $\mathrm{Db}$ & 0 & $\mathrm{Da}$ \\
\hline 2B587 & 0 & $\mathrm{Ea}$ & 100 & $\mathrm{Aa}$ & 100 & $\mathrm{Aa}$ & 100 & $\mathrm{Aa}$ & 50 & $\mathrm{Ce}$ & 55 & $\mathrm{Bd}$ & 6 & $\mathrm{Da}$ & 0 & $\mathrm{Ea}$ \\
\hline CV (\%) & \\
\hline
\end{tabular}

$\mathrm{CLE}=$ clethodim; QUI = quizalofop-p-ethyl; CLO = clodinafop; IMZ = imazethapyr; $[\mathrm{IMX}+\mathrm{BEN}]=[$ imazamox + bentazon $]$; CLS = cloransulan; GLY = glyphosate. * Médias seguidas por letras distintas maiúsculas na linha e minúsculas na coluna diferem entre si pelo teste de Scott-Knott $(\mathrm{p}<0,05)$.

ciado ao glyphosate (Tabela 4). No entanto, apenas três híbridos (CD384, SYN7205 e DKB390) foram controlados de forma aceitável agronomicamente por esse tratamento químico (controle variando entre 85 a 95\%). Ou seja, seis híbridos apresentaram níveis de controle após a aplicação de imazethapyr + glyphosate considerados insatisfatórios, o que de certa forma dificulta a recomendação desse tratamento para o controle de milho voluntário no estágio V6, e demonstra a variabilidade genotípica quanto a tolerância do milho a aplicação do referido herbicida.

A mistura pré-formulada de [imazamox + bentazon] associada com glyphosate não foi eficiente para o controle de plantas de milho provenientes de qualquer um dos híbridos avaliados (Tabela 4). O híbrido SYN 7205 foi o que apresentou maior sensibi- lidade a este tratamento, mesmo assim o controle verificado foi de $74 \%$, ou seja, abaixo do aceitável para fins de registro quanto a sua eficiência agronômica.

O herbicida cloransulan em mistura de tanque com glyphosate praticamente apresentou-se como um herbicida seletivo ao milho, quando aplicado em V6 (Tabela 4). Poucos sintomas foram observados decorrentes da ação deste tratamento herbicida aos 48 DAA, sendo que para dois híbridos (DKB177 e DKB390) as notas de controle foram nulas (zero), mostrando total ausência de injúrias.

Em relação aos herbicidas inibidores da ACCase somente foram observadas diferenças quanto a suscetibilidade entre os híbridos em relação a velocidade de controle. Os híbridos AS1633 e DKB390 apresentaram resposta mais lenta à ação do herbici- 
da clodinafop associado ao glyphosate, podendo ser visualizado tal efeito na avaliação realizada aos 14 DAA (Tabela 2). Já o híbrido CD3612 foi o único com controle abaixo de $80 \%$ na avaliação realizada aos 14 DAA, nas parcelas que receberam a aplicação de quizalofop-p-ethyl com glyphosate (Tabela 2). AS1633 e CD384 foram os únicos híbridos de milho que ainda possuíam plantas vivas aos 35 DAA (Tabela 4) após a aplicação de clethodim + glyphosate.

$\mathrm{Na}$ Tabela 5, podem ser analisados os resultados referentes à avaliação de altura de plantas aos 7 e 28 DAA dos diferentes tratamentos herbicidas visando o manejo químico de plantas voluntárias de milho $\mathrm{RR}^{\circledR}$. Aos 7 DAA, quase todos os tratamentos herbicidas promoveram redução na altura das plantas de milho. Os híbridos que não apresentaram reduções na altura de plantas nessa avaliação relacionados ao tratamento herbicida empregado foram CD384 com aplicação de quizalofop-p-ethyl e [imazamox + bentazon] em associação com glyphosate; 30S31 com aplicação de quizalofop-p-ethyl em associação com glyphosate; DKB390 e 2B587 com aplicação de quizalofop-p-ethyl e cloransulan em associação com glyphosate, além da utilização isolada do glyphosate.

$\mathrm{Na}$ avaliação seguinte, aos 28 DAA, observam-se reduções drásticas no porte das plantas de milho de todos os híbridos promovidas pela ação dos herbicidas, com exceção dos tratamentos cloransulan + glyphosate e glyphosate isolado, que causaram pequenas reduções no crescimento de alguns híbridos (Tabela 5). As plantas de milho de todos os híbridos que foram pulverizadas com quizalofop-p-ethyl e clo-

Tabela 5. Altura de plantas de milho resistentes ao glyphosate ( $\mathrm{cm})$ aos 7 e 28 dias após a aplicação de diferentes tratamentos herbicidas. Rio Verde-GO, 2015.

\begin{tabular}{|c|c|c|c|c|c|c|c|c|c|c|c|c|c|c|c|c|}
\hline \multirow{3}{*}{$\frac{\text { Híbrido }}{\text { AS1633 }}$} & \multicolumn{16}{|c|}{ Altura de plantas $(\mathrm{cm})-7$ DAA } \\
\hline & \multicolumn{2}{|c|}{ Testemunha } & \multicolumn{2}{|c|}{ CLE+GLY } & \multicolumn{2}{|c|}{ QUI+GLY } & \multicolumn{2}{|c|}{ CLO+GLY } & \multicolumn{2}{|c|}{ IMZ+GLY } & \multicolumn{2}{|c|}{$[\mathrm{IMX}+\mathrm{BEN}]+\mathrm{GLY}$} & \multicolumn{2}{|c|}{ CLS+GLY } & \multicolumn{2}{|c|}{ GLY } \\
\hline & 106 & $\mathrm{Aa}$ & 90 & $\mathrm{Ca}$ & 98 & $\mathrm{Ba}$ & 86 & $\mathrm{Ca}$ & 89 & $\mathrm{Ca}$ & 87 & $\mathrm{Cb}$ & 89 & $\mathrm{Ca}$ & 89 & $\mathrm{Ca}$ \\
\hline CD384 & 107 & $\mathrm{Aa}$ & 90 & $\mathrm{Ba}$ & 101 & Aa & 90 & $\mathrm{Ba}$ & 95 & $\mathrm{Ba}$ & 98 & $\mathrm{Aa}$ & 93 & $\mathrm{Ba}$ & 95 & $\mathrm{Ba}$ \\
\hline CD3612 & 104 & $\mathrm{Aa}$ & 94 & $\mathrm{Ba}$ & 95 & $\mathrm{Ba}$ & 84 & $\mathrm{Ba}$ & 93 & $\mathrm{Ba}$ & 90 & $\mathrm{Bb}$ & 90 & $\mathrm{Ba}$ & 90 & $\mathrm{Ba}$ \\
\hline $30 \mathrm{~S} 31$ & 105 & $\mathrm{Aa}$ & 88 & $\mathrm{Ba}$ & 97 & $\mathrm{Aa}$ & 87 & $\mathrm{Ba}$ & 90 & $\mathrm{Ba}$ & 93 & $\mathrm{Ba}$ & 92 & $\mathrm{Ba}$ & 90 & $\mathrm{Ba}$ \\
\hline $30 \mathrm{~F} 53$ & 102 & $\mathrm{Ab}$ & 85 & $\mathrm{Ba}$ & 88 & $\mathrm{Bb}$ & 80 & $\mathrm{Bb}$ & 83 & $\mathrm{Ba}$ & 84 & $\mathrm{Bb}$ & 85 & $\mathrm{Ba}$ & 83 & $\mathrm{Ba}$ \\
\hline SYN7205 & 100 & $\mathrm{Ab}$ & 83 & $\mathrm{Ba}$ & 88 & $\mathrm{Bb}$ & 85 & $\mathrm{Ba}$ & 86 & $\mathrm{Ba}$ & 84 & $\mathrm{Bb}$ & 89 & $\mathrm{Ba}$ & 90 & $\mathrm{Ba}$ \\
\hline DKB177 & 98 & $\mathrm{Ab}$ & 84 & $\mathrm{Ba}$ & 86 & $\mathrm{Bb}$ & 76 & $\mathrm{Cb}$ & 86 & $\mathrm{Ba}$ & 87 & $\mathrm{Bb}$ & 84 & $\mathrm{Ba}$ & 87 & $\mathrm{Ba}$ \\
\hline DKB390 & 97 & $\mathrm{Ab}$ & 89 & $\mathrm{Ba}$ & 98 & $\mathrm{Aa}$ & 87 & $\mathrm{Ba}$ & 90 & $\mathrm{Ba}$ & 82 & $\mathrm{Bb}$ & 96 & $\mathrm{Aa}$ & 93 & $\mathrm{Aa}$ \\
\hline 2B587 & 95 & $\mathrm{Ab}$ & 83 & $\mathrm{Ba}$ & 88 & $\mathrm{Ab}$ & 80 & $\mathrm{Bb}$ & 84 & $\mathrm{Ba}$ & 81 & $\mathrm{Bb}$ & 92 & $\mathrm{Aa}$ & 87 & $\mathrm{Aa}$ \\
\hline CV (\%) & & & & & & & & & 2,76 & & & & & & & \\
\hline \multirow{2}{*}{ Híbrido } & \multicolumn{16}{|c|}{ Altura de plantas $(\mathrm{cm})-28$ DAA } \\
\hline & \multicolumn{2}{|c|}{ Testemunha } & \multicolumn{2}{|c|}{ CLE+GLY } & \multicolumn{2}{|c|}{ QUI+GLY } & \multicolumn{2}{|c|}{ CLO+GLY } & \multicolumn{2}{|c|}{ IMZ+GLY } & \multicolumn{2}{|c|}{$[\mathrm{IMX}+\mathrm{BEN}]+\mathrm{GLY}$} & \multicolumn{2}{|c|}{ CLS+GLY } & \multicolumn{2}{|c|}{ GLY } \\
\hline AS1633 & 176 & $\mathrm{Ab}$ & 62 & $\mathrm{Ca}$ & 0 & $\mathrm{Da}$ & 0 & $\mathrm{Da}$ & 61 & $\mathrm{Cc}$ & 79 & $\mathrm{Bc}$ & 161 & $\mathrm{Aa}$ & 158 & $\overline{\mathrm{Ab}}$ \\
\hline CD384 & 187 & $\mathrm{Aa}$ & 52 & $\mathrm{Da}$ & 0 & $\mathrm{Ea}$ & 0 & $\mathrm{Ea}$ & 62 & Dc & 82 & $\mathrm{Cc}$ & 164 & $\mathrm{Ba}$ & 183 & $\mathrm{Aa}$ \\
\hline CD3612 & 176 & $\mathrm{Ab}$ & 37 & $\mathrm{Db}$ & 0 & $\mathrm{Ea}$ & 0 & $\mathrm{Ea}$ & 70 & $\mathrm{Cc}$ & 91 & $\mathrm{Bb}$ & 168 & $\mathrm{Aa}$ & 162 & $\mathrm{Ab}$ \\
\hline 30S31 & 192 & $\mathrm{Aa}$ & 0 & $\mathrm{Ec}$ & 0 & $\mathrm{Ea}$ & 0 & $\mathrm{Ea}$ & 103 & $\mathrm{Da}$ & 121 & $\mathrm{Ca}$ & 158 & $\mathrm{Ba}$ & 168 & $\mathrm{Bb}$ \\
\hline $30 F 53$ & 177 & $\mathrm{Ab}$ & 0 & Dc & 0 & $\mathrm{Da}$ & 0 & $\mathrm{Da}$ & 65 & $\mathrm{Cc}$ & 64 & $\mathrm{Cc}$ & 158 & $\mathrm{Ba}$ & 157 & $\mathrm{Bb}$ \\
\hline SYN7205 & 171 & $\mathrm{Ab}$ & 37 & $\mathrm{Cb}$ & 0 & $\mathrm{Da}$ & 0 & $\mathrm{Da}$ & 58 & $\mathrm{Bc}$ & 65 & $\mathrm{Bc}$ & 157 & $\mathrm{Aa}$ & 159 & $\mathrm{Ab}$ \\
\hline DKB177 & 197 & $\mathrm{Aa}$ & 16 & $\mathrm{Ec}$ & 0 & $\mathrm{Ea}$ & 0 & $\mathrm{Ea}$ & 58 & Dc & 100 & $\mathrm{Cb}$ & 162 & $\mathrm{Ba}$ & 164 & $\mathrm{Bb}$ \\
\hline DKB390 & 179 & $\mathrm{Ab}$ & 37 & $\mathrm{Db}$ & 0 & $\mathrm{Ea}$ & 0 & $\mathrm{Ea}$ & 62 & $\mathrm{Cc}$ & 70 & $\mathrm{Cc}$ & 161 & $\mathrm{Ba}$ & 163 & $\mathrm{Bb}$ \\
\hline 2B587 & 163 & $\mathrm{Ab}$ & 37 & $\mathrm{Cb}$ & 0 & $\mathrm{Da}$ & 0 & $\mathrm{Da}$ & 81 & $\mathrm{Bb}$ & 95 & $\mathrm{Bb}$ & 153 & $\mathrm{Aa}$ & 151 & $\mathrm{Ab}$ \\
\hline CV (\%) & \multicolumn{16}{|c|}{23,23} \\
\hline
\end{tabular}

$\mathrm{CLE}=$ clethodim; QUI = quizalofop-p-ethyl; CLO = clodinafop; IMZ = imazethapyr; $[\mathrm{IMX}+\mathrm{BEN}]=[\mathrm{imazamox}+$ bentazon $]$; CLS = cloransulan; GLY = glyphosate. *Médias seguidas por letras distintas maiúsculas na linha e minúsculas na coluna diferem entre si pelo teste de Scott-Knott $(\mathrm{p}<0,05)$. 
dinafop em associação com glyphosate já estavam todas mortas e prostradas rente ao solo nessa avaliação.

Tanto na avaliação de altura realizada aos 7 DAA, como na de 28 DAA, a utilização do glyphosate isolado proporcionou menores valores de altura em relação à testemunha para alguns híbridos. Esse comportamento foi mais evidente na primeira avaliação, e, excluindo os híbridos DKB390 e 2B587, todos os outros tiveram menores valores dessa variável quando comparados à testemunha. Na avaliação realizada aos 28 DAA, o comportamento de se verificar menores alturas para as plantas que receberam aplicação de glyphosate isolado só foi observado para os híbridos 30S31, 30F53, DKB177 e DKB390.

Na última avaliação de altura (48 DAA), verificou-se efeito completo de prostração e morte das plantas de milho de todos os híbridos relatados na avaliação anterior (28 DAA), que receberam aplicação de quizalofop-p-ethyl e clodinafop em associação com glyphosate (Tabela 6). Esse comportamento também foi verificado para as plantas de milho pulverizadas com o outro inibidor de ACCase avaliado (clethodim), fato que confirma, assim como a avaliação de controle visual, que esse herbicida, apesar de ser eficiente para controlar plantas de milho, apresenta ação mais lenta.

Também foi confirmada, nessa última avaliação de altura de plantas (48 DAA) a ação intermediária promovida pelos herbicidas imazethapyr e [imazamox + bentazon] nas plantas de milho. Estes são tóxicos, mas para a maioria dos híbridos não atingindo o patamar de eficiência necessária para serem uti-

Tabela 6. Altura de plantas de milho resistentes ao glyphosate $(\mathrm{cm})$ e porcentagem de redução da altura em relação à testemunha aos 48 dias após a aplicação de diferentes tratamentos herbicidas. Rio Verde-GO, 2015.

\begin{tabular}{|c|c|c|c|c|c|c|c|c|c|c|c|c|c|c|c|c|}
\hline \multirow{3}{*}{$\frac{\text { Híbrido }}{\text { AS1633 }}$} & \multicolumn{16}{|c|}{ Altura de plantas $(\mathrm{cm})-48$ DAA } \\
\hline & \multicolumn{2}{|c|}{ Testemunha } & \multicolumn{2}{|c|}{ CLE+GLY } & \multicolumn{2}{|c|}{ QUI+GLY } & \multicolumn{2}{|c|}{$\mathrm{CLO}+\mathrm{GLY}$} & \multicolumn{2}{|c|}{ IMZ+GLY } & \multicolumn{2}{|c|}{$[\mathrm{IMX}+\mathrm{BEN}]+\mathrm{GLY}$} & \multicolumn{2}{|c|}{ CLS+GLY } & \multicolumn{2}{|c|}{ GLY } \\
\hline & 186 & $\mathrm{Ab}$ & 0 & $\mathrm{Da}$ & 0 & $\mathrm{Da}$ & 0 & $\mathrm{Da}$ & 78 & $\mathrm{Cb}$ & 106 & $\mathrm{Bb}$ & 168 & $\mathrm{Ab}$ & 173 & $\overline{\mathrm{Aa}}$ \\
\hline CD384 & 182 & $\mathrm{Ab}$ & 0 & $\mathrm{Da}$ & 0 & $\mathrm{Da}$ & 0 & $\mathrm{Da}$ & 56 & $\mathrm{Cc}$ & 94 & $\mathrm{Bb}$ & 167 & $\mathrm{Ab}$ & 177 & $\mathrm{Aa}$ \\
\hline CD3612 & 175 & $\mathrm{Ab}$ & 0 & $\mathrm{Da}$ & 0 & $\mathrm{Da}$ & 0 & $\mathrm{Da}$ & 76 & $\mathrm{Cb}$ & 93 & $\mathrm{Bb}$ & 164 & $\mathrm{Ab}$ & 171 & $\mathrm{Aa}$ \\
\hline $30 \mathrm{~S} 31$ & 214 & $\mathrm{Aa}$ & 0 & $\mathrm{Da}$ & 0 & $\mathrm{Da}$ & 0 & $\mathrm{Da}$ & 137 & $\mathrm{Ca}$ & 154 & $\mathrm{Ca}$ & 200 & $\mathrm{Ba}$ & 190 & $\mathrm{Ba}$ \\
\hline $30 \mathrm{~F} 53$ & 167 & Ac & 0 & $\mathrm{Ca}$ & 0 & $\mathrm{Ca}$ & 0 & $\mathrm{Ca}$ & 75 & $\mathrm{Bb}$ & 60 & $\mathrm{Bd}$ & 163 & $\mathrm{Ab}$ & 160 & $\mathrm{Ab}$ \\
\hline SYN7205 & 159 & Ac & 0 & $\mathrm{Ca}$ & 0 & $\mathrm{Ca}$ & 0 & $\mathrm{Ca}$ & 49 & $\mathrm{Bc}$ & 58 & $\mathrm{Bd}$ & 151 & $\mathrm{Ab}$ & 159 & $\mathrm{Ab}$ \\
\hline DKB177 & 180 & $\mathrm{Ab}$ & 0 & $\mathrm{Ea}$ & 0 & $\mathrm{Ea}$ & 0 & $\mathrm{Ea}$ & 71 & $\mathrm{Db}$ & 103 & $\mathrm{Cb}$ & 160 & $\mathrm{Bb}$ & 177 & $\mathrm{Aa}$ \\
\hline DKB390 & 182 & $\mathrm{Ab}$ & 0 & $\mathrm{Da}$ & 0 & $\mathrm{Da}$ & 0 & $\mathrm{Da}$ & 50 & $\mathrm{Cc}$ & 78 & $\mathrm{Bc}$ & 175 & $\mathrm{Ab}$ & 172 & $\mathrm{Aa}$ \\
\hline 2B587 & 141 & Ad & 0 & $\mathrm{Ca}$ & 0 & $\mathrm{Ca}$ & 0 & $\mathrm{Ca}$ & 83 & $\mathrm{Bb}$ & 99 & $\mathrm{Bd}$ & 150 & $\mathrm{Ab}$ & 151 & $\mathrm{Ab}$ \\
\hline CV (\%) & & & & & & & & & 2,48 & & & & & & & \\
\hline \multirow{2}{*}{ Híbrido } & \multicolumn{16}{|c|}{ Redução de altura (\%) em relação à testemunha - 48 DAA } \\
\hline & \multicolumn{2}{|c|}{ Testemunha } & \multicolumn{2}{|c|}{ CLE+GLY } & \multicolumn{2}{|c|}{ QUI+GLY } & \multicolumn{2}{|c|}{ CLO+GLY } & \multicolumn{2}{|c|}{ IMZ+GLY } & \multicolumn{2}{|c|}{$[\mathrm{IMX}+\mathrm{BEN}]+\mathrm{GLY}$} & \multicolumn{2}{|c|}{ CLS+GLY } & \multicolumn{2}{|c|}{ GLY } \\
\hline AS1633 & 0 & $\mathrm{Da}$ & 100 & Aa & 100 & Aa & 100 & Aa & 58 & $\mathrm{Bb}$ & 43 & $\mathrm{Cb}$ & 10 & $\mathrm{Da}$ & 7 & $\overline{\mathrm{Da}}$ \\
\hline CD384 & 0 & $\mathrm{Da}$ & 100 & Aa & 100 & $\mathrm{Aa}$ & 100 & $\mathrm{Aa}$ & 69 & $\mathrm{Ba}$ & 48 & $\mathrm{Cb}$ & 8 & $\mathrm{Da}$ & 3 & $\mathrm{Da}$ \\
\hline CD3612 & 0 & $\mathrm{Da}$ & 100 & $\mathrm{Aa}$ & 100 & $\mathrm{Aa}$ & 100 & $\mathrm{Aa}$ & 56 & $\mathrm{Bb}$ & 47 & $\mathrm{Cb}$ & 6 & $\mathrm{Da}$ & 2 & Da \\
\hline 30S31 & 0 & $\mathrm{Da}$ & 100 & $\mathrm{Aa}$ & 100 & $\mathrm{Aa}$ & 100 & $\mathrm{Aa}$ & 36 & $\mathrm{Bc}$ & 28 & $\mathrm{Bc}$ & 6 & $\mathrm{Ca}$ & 11 & $\mathrm{Ca}$ \\
\hline $30 \mathrm{~F} 53$ & 0 & $\mathrm{Da}$ & 100 & $\mathrm{Aa}$ & 100 & $\mathrm{Aa}$ & 100 & $\mathrm{Aa}$ & 55 & $\mathrm{Cb}$ & 64 & $\mathrm{Ba}$ & 2 & $\mathrm{Da}$ & 4 & $\mathrm{Da}$ \\
\hline SYN7205 & 0 & $\mathrm{Ca}$ & 100 & $\mathrm{Aa}$ & 100 & $\mathrm{Aa}$ & 100 & $\mathrm{Aa}$ & 70 & $\mathrm{Ba}$ & 64 & $\mathrm{Ba}$ & 5 & $\mathrm{Ca}$ & 0 & $\mathrm{Ca}$ \\
\hline DKB177 & 0 & $\mathrm{Ea}$ & 100 & $\mathrm{Aa}$ & 100 & $\mathrm{Aa}$ & 100 & $\mathrm{Aa}$ & 61 & $\mathrm{Bb}$ & 43 & $\mathrm{Cb}$ & 11 & $\mathrm{Da}$ & 2 & $\mathrm{Ea}$ \\
\hline DKB390 & 0 & $\mathrm{Da}$ & 100 & $\mathrm{Aa}$ & 100 & $\mathrm{Aa}$ & 100 & $\mathrm{Aa}$ & 73 & $\mathrm{Ba}$ & 57 & $\mathrm{Ca}$ & 4 & $\mathrm{Da}$ & 6 & $\mathrm{Da}$ \\
\hline 2B587 & 0 & $\mathrm{Da}$ & 100 & $\mathrm{Aa}$ & 100 & $\mathrm{Aa}$ & 100 & $\mathrm{Aa}$ & 41 & $\mathrm{Bc}$ & 30 & $\mathrm{Cc}$ & 0 & $\mathrm{Da}$ & 0 & $\mathrm{Da}$ \\
\hline CV (\%) & & & & & & & & & & & & & & & & \\
\hline
\end{tabular}

$\mathrm{CLE}=$ clethodim; $\mathrm{QUI}=$ quizalofop-p-ethyl $\mathrm{CLO}=$ clodinafop IMZ = imazethapyr; $[\mathrm{IMX}+\mathrm{BEN}]=[$ imazamox + bentazon $]$; CLS $=$ cloransulan; GLY = glyphosate. *Médias seguidas por letras distintas maiúsculas na linha e minúsculas na coluna diferem entre si pelo teste de Scott-Knott $(\mathrm{p}<0,05)$. 
lizados nessa modalidade. Todos os híbridos de milho que receberam a aplicação de cloransulan + glyphosate e glyphosate isolado apresentaram altura de plantas similar à testemunha, com exceção do híbrido 30S31, que sofreu pequenas reduções no porte quando recebeu os tratamentos cloransulan + glyphosate e glyphosate, e o híbrido DKB177, com a aplicação de cloransulan + glyphosate.

Ainda na Tabela 6, estão apresentados os resultados de porcentagem de redução na altura em relação à respectiva testemunha de cada híbrido de milho, sendo considerados para esta análise os dados da avaliação realizada aos 48 DAA. Para todos os híbridos, os herbicidas inibidores da ACCase proporcionaram redução máxima nos valores de altura (100\%).

O imazethapyr associado ao glyphosate consistiu no segundo grupo de tratamentos que proporcionou maiores reduções na altura de plantas de milho, sendo as reduções neste tratamento superiores ao do [imazamox + bentazon] + glyphosate em seis dos nove híbridos de milho avaliados. Para os tratamentos com aplicação de clorasulan + glyphosate ou glyphosate isolado, as reduções na altura não extrapolaram porcentagens superiores a $11 \%$.

Comparando o efeito dos herbicidas sobre cada híbrido de milho, a partir dos resultados de porcentagem de redução de altura em relação à respectiva testemunha, verifica-se que tanto para imazethapyr como [imazamox + bentazon], ambos tratamentos aplicados em associação com glyphosate, os híbridos que apresentaram menores porcentagens de redução foram $30 \mathrm{~S} 31$ e $2 \mathrm{~B} 587$.

\section{Conclusões}

Os híbridos de milho AS 1633 PRO2, 30S31 YHR, 30F53 YHR, SYN 7205 TL/TG, DKB 177
PRO 3, DKB 390 PRO 3 e 2B587 PW (híbridos simples); CD 384 PW (híbrido triplo); e CD 3612 PW (híbrido simples modificado) podem ser controlados em estádio V6 com a aplicação dos herbicidas inibidores da ACCase quizalofop-p-ethyl, clodinafop -propargyl e clethodim, todos em associação com glyphosate.

O herbicida clethodim apresenta ação mais lenta no controle de plantas de milho em relação aos outros inibidores da ACCase avaliados.

A adição do glyphosate junto com os herbicidas inibidores da ACCase não impede que estes promovam excelente controle das plantas de milho resistentes ao glyphosate.

O imazethapyr associado ao glyphosate é eficiente no controle de plantas de milho somente dos híbridos DKB390, SYN7025 e CD384, os quais mostram maior suscetibilidade a esse tratamento em comparação aos demais híbridos avaliados.

\section{Referências}

BERTOL, I.; ALBUQUERQUE, J. A.; LEITE, D.; AMARAL, A. J.; ZOLDAN JÚNIOR, W. A. Propriedades físicas do solo sob preparo convencional e semeadura direta em rotação e sucessão de culturas, comparadas às do campo nativo. Revista Brasileira de Ciência do Solo, Viçosa, v. 28, n. 1, p. 155-163, 2004.

DOI: $10.1590 / \mathrm{S} 0100-06832004000100015$.

BIANCHI, M. A. Avaliação da eficiência e seletividade de clethodim sobre milho voluntário (Zea mays L.) na cultura da soja. In: RESULTADOS de pesquisa: controle de plantas daninhas 1993 a 2008. Cruz Alta: Fecotrigo, 2009. p. $178-180$.

BRAZ, G. B. P.; OLIVEIRA JÚNIOR, R. S.; CONSTANTIN, J.; OLIVEIRA NETO, A. M.; DAN H. A.; GUERRA, N.; OSIPE, J. B.; TAKANO, H. K. Alternativas para o controle de soja $\mathrm{RR}^{\circledR}$ voluntária na cultura do 
algodoeiro. Bioscience Journal, Uberlândia, v. 29, n. 2, p. 360-369, 2013.

BURKE, I. C.; THOMAS, W. E.; BURTON, J. D.; SPEARS, J. F.; WILCUT, J. W. A seedling assay to screen aryloxyphenoxypropionic acid and cyclohexanedione resistance in johnsongrass (Sorghum halepense). Weed Technology, Champaign, v. 20, n. 4, p. 950-955, 2006. DOI: 10.1614/WT-05-160.1.

CAVALIERI, S. D.; OLIVEIRA JÚNIOR, R. S.; CONSTANTIN, J.; BIFFE, D. F.; RIOS, F. A.; FRANCHINI, L. H. M. Tolerância de híbridos de milho ao herbicida nicosulfuron. Planta Daninha, Viçosa, v. 26, n. 1, p. 203-214, 2008.

DOI: $10.1590 / \mathrm{S} 0100-83582008000100021$.

CHAHAL, P. S.; KRUGER, G.; BLANCO-CANQUI, H.; JHALA, A. J. Efficacy of pre-emergence and postemergence soybean herbicides for control of glufosinate, glyphosate, and imidazolinone resistant volunteer corn. Journal of Agricultural Science, Toronto, v. 6, n. 8, p. 131-140, 2014.

DOI: 10.5539/jas.v6n8p131.

CORREIA, N. M.; DURIGAN, J. C.; ESPANHOL, M. Manejo de plantas daninhas em soja geneticamente modificada tolerante ao glyphosate. Pesquisa Agropecuária Tropical, Goiânia, v. 41, n. 2, p. 242-247, 2011.

DOI: $10.5216 /$ pat.v41i2.8807.

COSTA, N. V.; ZOBIOLE, L. H. S.; SCARIOT, C. A.; PEREIRA, G. R.; MORATELLI, G. Glyphosate tolerant volunteer corn control at two development stages. Planta Daninha, Viçosa, v. 32, n. 4, p. 675-682, 2014.

DOI: $10.1590 / \mathrm{S} 0100-83582014000400002$.

FERREIRA, D. F. Sisvar: a computer statistical analysis system. Ciência e Agrotecnologia, Lavras, v. 35, n. 6, p. 1039-1042, 2011.

DOI: $10.1590 / \mathrm{S} 1413-70542011000600001$.

GASPARIM, E.; RICIERI, R. P.; SILVA, S. L.; DALLACORT, R.; GNOATTO, E. Temperatura no perfil do solo utilizando duas densidades de cobertura e solo nu. Acta Scientiarum. Agronomy, Maringá, v. 27, n. 1, p. 107-115, 2005.

DOI: 10.4025/actasciagron.v27i1.2127.

LÓPEZ-OVEJERO, R. F.; SOARES, D. J.; OLIVEIRA, N. C.; KAWAGUCHI, I. T.; BERGER, G. U.; CARVALHO, S. J. P.; CHRISTOFFOLETI, P. J. Interferência e controle de milho voluntário tolerante ao glifosato na cultura da soja. Pesquisa Agropecuária Brasileira, Brasília, v. 51, n. 4, p. 340-347, 2016.

DOI: 10.1590/S0100-204X2016000400006.

MARCA, V.; PROCÓPIO, S. O.; SILVA, A. G.; VOLF, M. Chemical control of glyphosate-resistant volunteer maize. Revista Brasileira de Herbicidas, Londrina, v. 14, n. 2, p. 103-110, 2015.

DOI: $10.7824 /$ rbh.v14i2.408.

MARQUARDT, P. T.; JOHNSON, W. G. Influence of clethodim application timing on control of volunteer corn in soybean. Weed Technology, Champaign, v. 27, n. 4, p. 645-648, 2013.

DOI: 10.1614/WT-D-12-00188.1.

NALEWAJA, J. D.; MATYSIAK, R.; SZELEZNIAK, E. F. Sethoxydim response to spray chemical properties and environment. Weed Technology, Champaign, v. 8, n. 3, p. 591-597, 1994.

DOI: $10.1017 / \mathrm{S} 0890037 X 00039749$.

PETTER, F. A.; SIMA, V. M.; FRAPORTI, M. B.; PEREIRA, C. S.; PROCÓPIO, S. O.; SILVA, A. F. Volunteer $\mathrm{RR}^{\circledR}$ corn management in roundup ready ${ }^{\circledR}$ soybean-corn succession system. Planta Daninha, Viçosa, v. 33, n. 1, p. 119-128, 2015.

DOI: $10.1590 / \mathrm{S} 0100-83582015000100014$.

SANTOS, H. G. dos; JACOMINE, P. K. T.; ANJOS, L. H. C. dos; OLIVEIRA, V. A. de; LUMBRERAS, J. F.; COELHO, M. R.; ALMEIDA, J. A. de; CUNHA, T. J. F.; OLIVEIRA, J. B. de. Sistema brasileiro de classificação de solos. 3. ed. rev. e ampl. Brasília, DF: Embrapa, 2013. $353 \mathrm{p}$. 
VELINI, E. D.; OSIPE, R.; GAZZIERO, D. L. P. ZABLOTOWICZ, R. M.; WEAVER, M. A.; LOCKE, (Coord.). Procedimentos para instalação, avaliação M. A. Microbial adaptation for accelerated atrazine e análise de experimentos com herbicidas. Londrina: mineralization/degradation in Mississippi Delta soils. Sociedade Brasileira da Ciência das Plantas Daninhas, $\quad$ Weed Science, Champaign, v. 54, n. 3, p. 538-547, 2006. 1995. 42 p. DOI: 10.1614/WS-04-179R3.1. 